\title{
Electrical Conductivity of Spark Plasma Sintered W-Cu and Mo-Cu Composites for Electrical Contact Applications
}

\author{
N. I. Amalu1, B. A. Okorie ${ }^{2,3}$, J. C. Ugwuoke², C. S. Obayi ${ }^{3}$ \\ ${ }^{1}$ Projects Development Institute, (PRODA), Enugu, Nigeria \\ ${ }^{2}$ Department of Metallurgical and Materials Engineering, Enugu State University of Science and Technology, Enugu, Nigeria \\ ${ }^{3}$ Department of Metallurgical \& Materials Engineering, University of Nigeria, Nsukka, Nigeria \\ Email: ninablaise5050@gmail.com, bonokorie@yahoo.com, joseph.ugwuoke@esut.edu.ng, camillus.obayi@unn.edu.ng
}

How to cite this paper: Amalu, N.I., Okorie, B.A., Ugwuoke, J.C. and Obayi, C.S. (2021) Electrical Conductivity of Spark Plasma Sintered W-Cu and Mo-Cu Composites for Electrical Contact Applications. Journal of Minerals and Materials Characterization and Engineering, 9, 48-60.

https://doi.org/10.4236/jmmce.2021.91004

Received: November 16, 2020

Accepted: January 15, 2021

Published: January 18, 2021

Copyright $\odot 2021$ by author(s) and Scientific Research Publishing Inc. This work is licensed under the Creative Commons Attribution International License (CC BY 4.0).

http://creativecommons.org/licenses/by/4.0/

\begin{abstract}
Tungsten copper and molybdenum copper composites, with weight percent copper in the range of $20 \%-40 \%$, have been produced using the spark plasma sintering (SPS) technique. Other specimens having similar compositions were also developed using the conventional techniques of Liquid Phase Sintering (LPS) and Infiltration. Electrical conductivity measurements showed that the specimens produced by the SPS process had substantially higher levels of electrical conductivity than those produced by the other methods. Relative density measurements showed that the SPS specimens achieved very high densification, with relative densities in the range of $99.1 \%-100 \%$. On the other hand, the specimens produced by LPS and infiltration had relative densities in the range of $88 \%-92 \%$ and $96 \%-98 \%$ respectively. The superior conductivity of the SPS specimens has been attributed to the virtually full densification achieved by the process. The effect of porosity on electrical conductivity has been discussed and three standard models were assessed using results from porous sintered skeletons of pure tungsten and pure molybdenum.
\end{abstract}

\section{Keywords}

Sintering, Infiltration, Conductivity, Porosity, Spark Plasma,

Electrical Contact, Relative Density

\section{Introduction}

Electrical contacts are generally made from metals of high electrical conductivity such as alloys of silver, copper, gold, platinum and palladium. These types of 
contact materials are commonly produced by liquid metallurgy processing techniques. The basic properties required from such contact materials are good electrical conductivity, corrosion resistance, hardness, and fairly good resistance to mechanical wear. For some industrial applications, however, such as high-power equipment brushes, there is a need for a substantially high hardness and high resistance to abrasive wear. Refractory based electrical contacts are required for such applications.

Refractory metals such as tungsten and molybdenum have limited current carrying capacity due to their relatively low electrical conductivity and high contact resistance even with high contact forces. However, because of their high melting points and boiling points, they offer very high resistance to mechanical wear, electrical arc erosion and welding, and are therefore very good electrical contact materials where these special properties are required. Their electrical conductivity can be enhanced by developing them in the form of composites with metals such as copper and silver. The aim here is to combine the high melting point and arc erosion resistance of $\mathrm{W}$ or Mo with the low melting point and high electrical conductivity of copper $(\mathrm{Cu})$.

Composite materials such as $\mathrm{W}-\mathrm{Cu}, \mathrm{Mo}-\mathrm{Cu}, \mathrm{W}-\mathrm{Ag}$ and $\mathrm{Mo}-\mathrm{Ag}$ are generally produced using techniques such as Powder Metallurgy (PM), Powder Injection Moulding (PIM), Metal Injection Moulding (MIM), High Energy Ball Milling (or Mechanical Alloying), and other related techniques which exclude the basic solidification processing techniques of melting and casting because of the high melting points of the refractory metals tungsten $\left(3410^{\circ} \mathrm{C}\right)$ and molybdenum $\left(2610^{\circ} \mathrm{C}\right)$. Details of such related techniques are available in the literature [1] [2] [3] [4] [5].

The two main powder metallurgy processes employed for the commercial production of the composites are Infiltration and Liquid Phase Sintering (LPS). In the LPS process, the tungsten (or molybdenum) powder is thoroughly blended with the copper powder and the blend is compacted and then sintered in a furnace at a temperature higher than the melting point of copper. Thus the copper melts and flows to fill the voids between the particles of tungsten (or molybdenum), after which the composite is cooled down to room temperature. In the Infiltration process, on the other hand, the pure tungsten (or molybdenum) powder is compacted and sintered in a furnace at a suitable temperature to obtain porous sintered skeletons of pure W (or Mo). Subsequently an appropriate amount of copper is placed on top of the sintered skeletons and heated in a furnace. The copper melts and is drawn by capillary forces to fill the pores in the pre-sintered skeletons. Although the infiltration process is a less cost-efficient process than the LPS process, and is a laborious, time-consuming two-stage thermal cycle process, it has a broad practical range of applications and is the preferred process in the electrical contact manufacturing industry. The composites produced by both the infiltration and LPS processes are generally within the 10 - $40 \mathrm{wt} \%$ Cu range [6].

The Spark Plasma Sintering (SPS) process, otherwise called the Pulsed Electric 
Current Sintering (PECS) process is a much more recent process that is not yet commercially available on a large scale. The mechanism of the method is based on the micro-spark discharge in the gap between neighbouring powder particles. It uses a simultaneous application of temperature and pressure, under a vacuum or inert gas environment to achieve high densification of the powder material. The heating rate is high (typically $1000^{\circ} \mathrm{C} / \mathrm{min}$.) and the temperatures used are generally lower by $200^{\circ} \mathrm{C}$ to $250^{\circ} \mathrm{C}$ than temperatures used in conventional sintering [7] [8].

The SPS process is now applied extensively in the dielectric, piezoelectric, and thermoelectric fields [9] [10] [11] and in the processing of transparent ceramics [12] [13] [14] [15]. Significant work has also been done on the effect of the process on the microstructure and mechanical properties of composites [16]. However no significant work appears to have been done to explore the applicability of the process to the electrical contact materials manufacturing industry. Since the SPS technique is known to yield good densification of sintered products, it is likely to be satisfactory for electrical contact material production. There is indeed the possibility that the spark plasma sintered $\mathrm{W}-\mathrm{Cu}$ and $\mathrm{Mo}-\mathrm{Cu}$ compacts may have better properties, such as higher electrical conductivity, higher hardness and better wear resistance than both the LPS and Infiltration processes. This paper presents results of a comparative study on the electrical conductivity of LPS, Infiltration, and SPS-produced sintered compacts for electrical contact applications.

\section{Experimental}

\subsection{Materials and Equipment}

The materials used for this research work include powder specimens of tungsten, molybdenum, and copper, procured from vendors in the United Kingdom and the United States of America, while the equipment used include a turbular mixer, a Spark plasma sintering machine (Turbula system Shatz, Willy A. Bashoten AG, Maschinenfarrik, Switzerland) graphite moulds, a pneumatic single action press, steel dies, a controlled atmosphere sintering furnace, and an electrical conductivity measuring facility.

\subsection{Experimental Methods}

\subsubsection{Production of Spark Plasma Sintered Specimens}

Figure 1(a) and Figure 1(b) show the image of the Spark Plasma Sintering (SPS) machine used to produce the experimental specimens in the Engineering laboratories of the Tshwane University of Technology, Pretoria, South Africa. Seven metal powder blends were prepared having the compositions detailed in Table 1. Each blend was placed in a Turbular mixer and thoroughly tumbled for ten (10) hours. For the compaction and sintering operation, graphite dies of various diameters were available for use, and from these, dies of diameter $15 \mathrm{~mm}$ were selected. Specimens of diameter $15 \mathrm{~mm}$ and thickness $5 \mathrm{~mm}$ were thus produced for measurement of electrical and mechanical properties. 


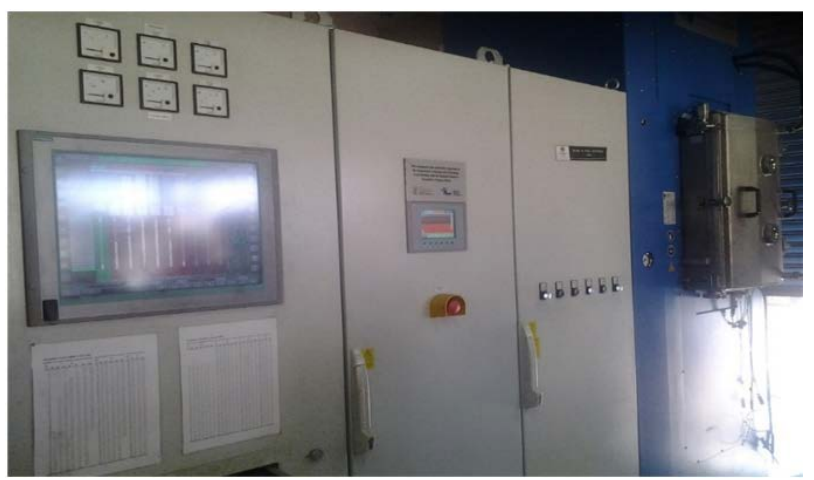

(a)

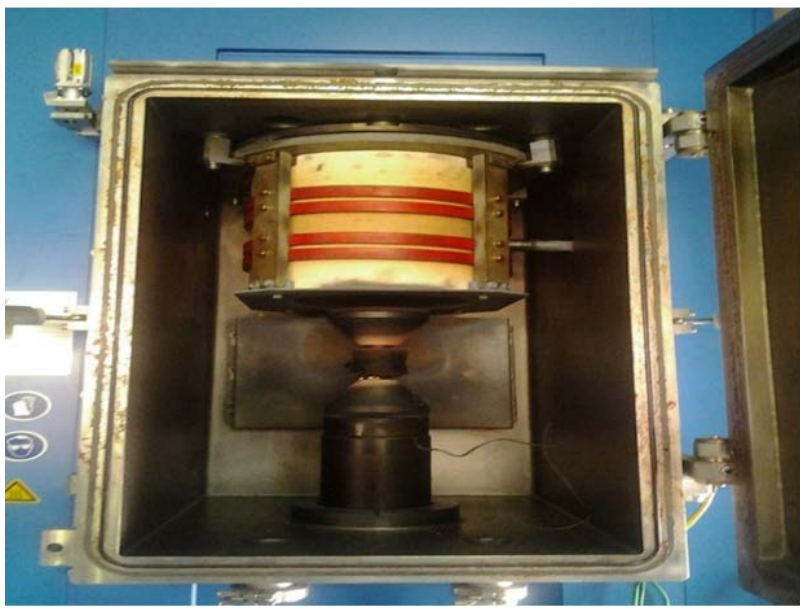

(b)

Figure 1. (a) Spark Plasma Sintering (SPS) Machine, and (b) Inside view of the SPS machine.

Table 1. Compositions of powder blends used in the SPS machine.

\begin{tabular}{cl}
\hline W-Cu Samples & Mo-Cu Samples \\
\hline 1) $\mathrm{W}-20 \mathrm{wt} \% \mathrm{Cu}$ & 1) $\mathrm{Mo}-20 \mathrm{wt} \% \mathrm{Cu}$ \\
2) $\mathrm{W}-30 \mathrm{wt} \% \mathrm{Cu}$ & 2) $\mathrm{Mo}-30 \mathrm{wt} \% \mathrm{Cu}$ \\
3) $\mathrm{W}-40 \mathrm{wt} \% \mathrm{Cu}$ & 3) $\mathrm{Mo}-40 \mathrm{wt} \% \mathrm{Cu}$ \\
\hline
\end{tabular}

Each powder mixture was placed in the dies between matching graphite punches and then placed in the SPS machine which combines the compaction process and the sintering at the same time in a vacuum environment. The SPS parameters determined for the present work were as follows:

Heating rate $=100^{\circ} \mathrm{C} /$ minute.

Sintering temperature $=1000^{\circ} \mathrm{C}$.

Dwell time $=10$ minutes.

Pressure $=40 \mathrm{MPa}$.

These parameters were used in the production of all the specimens. The cooling rate after the dwell time was also selected as $100^{\circ} \mathrm{C} /$ minute.

For purposes of assessment and comparison of specimen properties, sintered 
$\mathrm{W}-\mathrm{Cu}$ and $\mathrm{Mo}-\mathrm{Cu}$ specimens were also produced using the contact infiltration and liquid phase sintering (LPS) processes.

\subsubsection{Electrical Conductivity Measurements}

The electrical conductivity of the specimens was measured using an electrical conductivity testing device based on the schematic diagram shown in Figure 2. From the figure, it is noted from the ammeter and voltmeter readings (current $I$ and voltage $V$ ), that the resistance $R$ of the specimen is given by

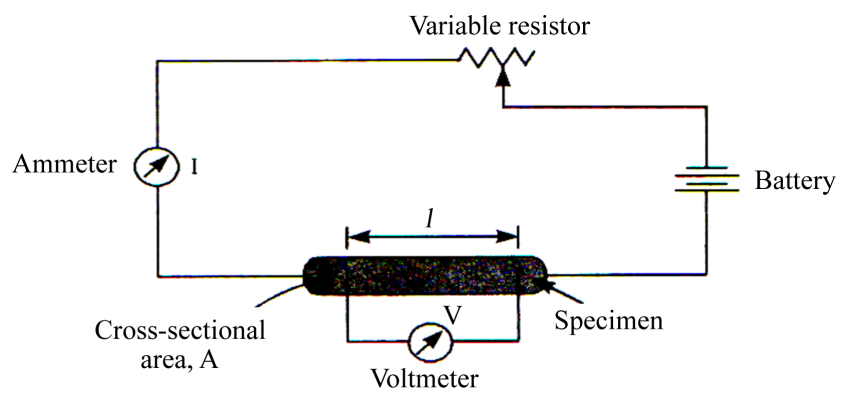

Figure 2. Circuit diagram for electrical conductivity measurement.

$$
R=\frac{V}{I} \operatorname{ohms}(\Omega)
$$

Also,

$$
R=\rho \frac{\ell}{A}(\Omega)
$$

where $\rho=\operatorname{resistivity~}(\Omega \cdot \mathrm{m})$

$\ell=$ length of specimen $(\mathrm{m})$

$A=$ cross-sectional area of specimen $\left(\mathrm{m}^{2}\right)$

From (2), we have

$$
\begin{gathered}
\rho=R \frac{A}{\ell} \\
\text { conductivity } \sigma=\frac{1}{\rho}=\frac{l}{R A}=\frac{I l}{V A}\left(\Omega^{-1} \cdot \mathrm{m}^{-1}\right)
\end{gathered}
$$

The conductivity values were recorded in terms of percent IACS (International Annealed copper standard), where the conductivity of commercial annealed copper at $20^{\circ} \mathrm{C}$ which is $5.8001 \times 10^{7}(\Omega-\mathrm{m})^{-1}$ or $5.8001 \times 10^{7}$ Siemens/metre is defined to be $100 \%$ IACS.

The relative densities of all the specimens were measured.

\section{Results and Discussion}

\subsection{Electrical Conductivity Results}

The results obtained from electrical conductivity measurements are presented in Figure 3 and Figure 4 for the $\mathrm{W}-\mathrm{Cu}$ and $\mathrm{Mo}-\mathrm{Cu}$ composite compacts, respectively. 


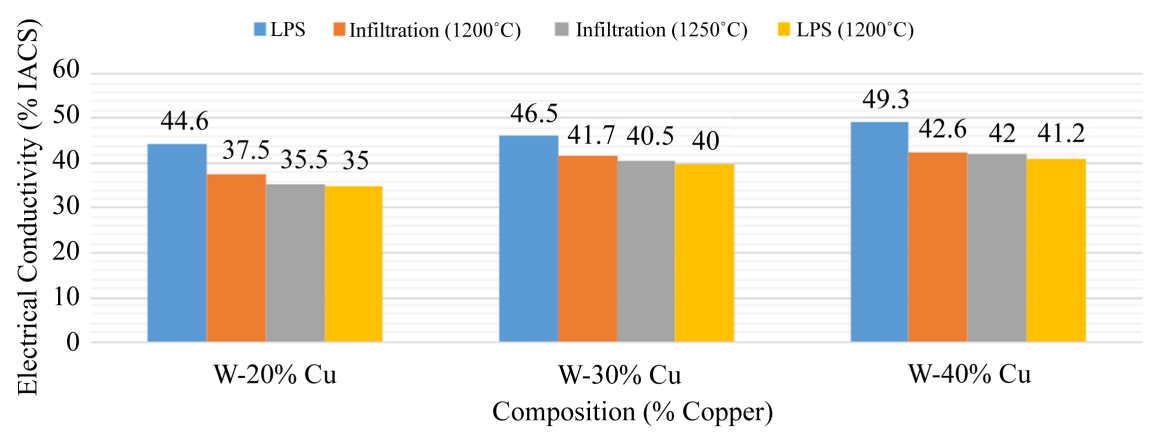

Figure 3. Electrical conductivity (\% IACS) of W-Cu specimens produced by SPS, infiltration, and LPS techniques.

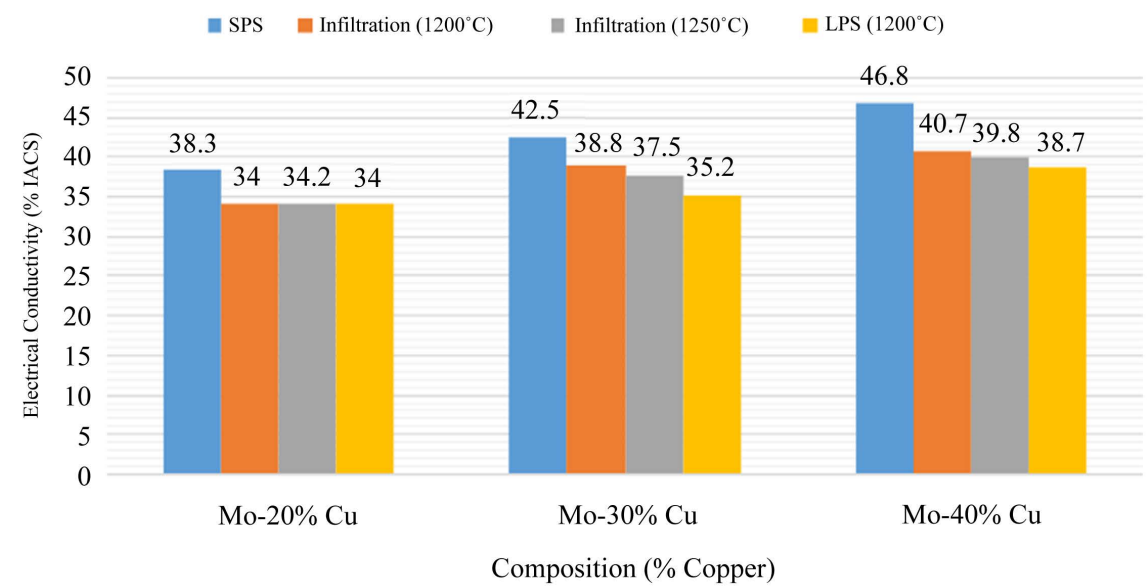

Figure 4. Electrical conductivity (\% IACS) of Mo-Cu specimens produced by SPS, infiltration and LPS techniques.

The Figures show clearly that the specimens produced by the Spark Plasma Sintering (SPS) process have substantially higher electrical conductivity than those produced by either the contact infiltration process or the liquid phase sintering (LPS) technique. This may be attributed to the very high level of densification (low level of porosity) in the specimens obtained by the SPS technique. Relative density test results showed that the relative densities of specimens produced by Liquid Phase Sintering ranged from $90 \%-92 \%$ for W-Cu compacts with composition in the $20 \mathrm{wt} \% \mathrm{Cu}$ to $40 \mathrm{wt} \% \mathrm{Cu}$ range, and $88 \%$ to $90 \%$ for $\mathrm{Mo}-\mathrm{Cu}$ compacts with copper in the same composition range. For the specimens produced by contact infiltration, the relative densities of the specimens ranged from $96.6 \%$ to $98 \%$ for the $\mathrm{W}-\mathrm{Cu}$ specimens and $96.2 \%$ to $96.8 \%$ for the $\mathrm{Mo}-\mathrm{Cu}$ specimens. On the other hand, all the specimens produced by the Spark Plasma Sintering process (with wt $\%$ copper within the same $20 \%-40 \%$ range) had relative densities in the $99.1 \%$ to $100 \%$ range. The full densification often obtained from the SPS technique is a result of the three-stage process of plasma heating from the pulsed D.C. power supply, joule heating, and plastic deformation due to the simultaneous application of heat and compaction pressure.

The following points may also be noted from Figure 3 and Figure 4 . 
- The conductivities increase, as expected, with increase in copper content.

- The W-Cu specimens have higher conductivity than comparative Mo-Cu specimens. Fully dense pure tungsten and molybdenum materials have approximately equal electrical conductivities of $30.86 \%$ IACS. However, it is clear that for composites having equal weight percentages of $\mathrm{Cu}$ (e.g. W-20\% $\mathrm{Cu}$ and $\mathrm{Mo}-20 \% \mathrm{Cu}$ ) the $\mathrm{W}-\mathrm{Cu}$ composite will contain a larger quantity (higher volume \%) of copper because of the higher density of tungsten as compared to molybdenum.

- The specimens produced by the infiltration process have, on average, conductivities that are slightly higher than those produced by the LPS process.

The values of electrical conductivity obtained in the present work are comparable with those reported in the literature for $\mathrm{W}-\mathrm{Cu}, \mathrm{Mo}-\mathrm{Cu}, \mathrm{W}-\mathrm{Ag}$ and $\mathrm{Mo}-\mathrm{Ag}$ specimens [17] [18] [19] [20] [21]. However, the values of conductivity obtained by the SPS technique in this work (for example $49.3 \%$ IACS and $46.8 \%$ IACS for $\mathrm{W}-40 \mathrm{Cu}$ and $\mathrm{Mo}-40 \mathrm{Cu}$ respectively) are higher than those reported. Comparative results in the literature give IACS values in the range of $40 \%-43 \%$ for $\mathrm{W}-40$ wt $\% \mathrm{Cu}$ produced by infiltration.

\subsection{Effect of Porosity on Electrical Conductivity}

The porosity of engineering materials affects a wide range of their properties, such as their thermal, electrical, mechanical, acoustic and damping properties. There are several analytical models in the literature aimed at addressing some of the problems associated with the effects of porosity on properties [22]-[28]. Here, two model equations based on the Effective Medium Theory (EMT), are presented and compared with a third model provided by Montes et al. [29].

\section{1) The Maxwell-Garnett Equation}

The Maxwell-Garnett model (Maxwell (1998)) aims at calculating the effective conductivity of a mixture of two phases-a continuous or matrix phase, and a dispersed phase (e.g. pores). The equation is

$$
\frac{\sigma_{e f}-\sigma_{m}}{\sigma_{e f}+2 \sigma_{m}}-p_{i} \frac{\sigma_{i}-\sigma_{m}}{\sigma_{i}+2 \sigma_{m}}=0
$$

where $\sigma_{e f}=$ Effective conductivity.

$\sigma_{m}=$ Conductivity of the continuous matrix.

$\sigma_{i}=$ Conductivity of the spherical particle inclusions.

$p_{i}=$ Volume fraction of the inclusions.

\section{2) The Bruggeman Approximation}

This EMT model, [30] [31] [32] has been used to predict the electrical properties of two-phase composites. The model equation is as follows:

$$
\left(1-p_{i}\right) \frac{\sigma_{m}-\sigma_{e f}}{\sigma_{m}+\sigma_{e f}}+p_{i} \frac{\sigma_{i}-\sigma_{e f}}{\sigma_{i}+2 \sigma_{e f}}=0
$$

where $\sigma_{e f} \sigma_{m}, \sigma_{i}$ and $p_{i}$ are defined the same as for Equation (5) above.

The Bruggeman approximation has a broader applicability range than the 
Maxwell-Garnett equation which is ideal only for dilute composite media.

For porous materials, we may put $\sigma_{i}=\sigma_{\text {pores }}=0$, and $\sigma_{m}=\sigma_{d}=$ conductivity of the fully dense material. Thus Equations (5) and (6) above become:

$$
\begin{gathered}
\sigma_{e f}=\sigma_{d} \frac{(1-p)}{\left(1+\frac{p}{2}\right)} \quad \text { (Maxwell-Garnett) } \\
\sigma_{e f}=\sigma_{d} \frac{(2-3 p)}{2} \text { (Bruggeman) }
\end{gathered}
$$

where $p=$ pore volume fraction, and $\sigma_{d}=$ conductivity of the fully dense matrix material.

\section{3) The Montes Model}

The two models presented above assume the pores to be spherical and cannot therefore give very satisfactory results for the case of pores in powder metallurgy processed metallic composites. In this case, the pore sizes, pore distribution and actual pore geometry and orientation should be given due consideration. Considering these factors, Montes and his co-workers [25] arrived at the model equation given as

$$
\sigma_{p}=\sigma_{d} \frac{\left(1-\frac{\varphi}{\varphi_{0}}\right)^{2}}{1-\varphi}
$$

where $\sigma_{p}=$ Conductivity of the porous sintered compact.

$\sigma_{d}=$ Conductivity of the fully dense material.

$\varphi=$ porosity of the sintered compact.

$\varphi_{0}=$ porosity of the vibrated starting powder mass.

Equation (9) is obtained based on a proper analysis of the effective path lengths and cross sectional areas for electron movement over a length $L$ of a fully dense specimen (Figure 5(a)), and a porous specimen (Figure 5(b)).

The subscripts $d$ and $p$ for the path lengths $\left(L_{d}\right.$ and $\left.L_{p}\right)$, and areas $\left(A_{d}\right.$ and $\left.A_{p}\right)$ refer to the dense specimen and the porous specimen, respectively. From Figure 5 , it may be noted that $L_{d}=L ; L_{p}>L_{\dot{d}}$ and $A_{p}<A_{d}$.

Equation (9) is obtained [25], based on theoretical expressions proposed for the relationships between $A_{p}$ and $A_{d}$ and between $L_{p}$ and $L_{d}$ for sintered powder products. These expressions are:

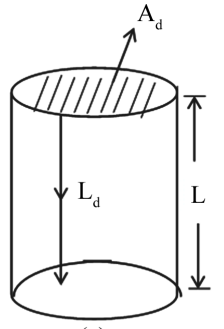

(a)

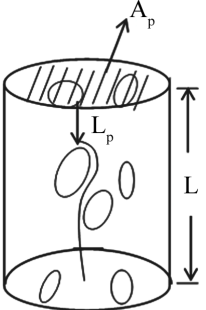

(b)

Figure 5. Effective conduction path length and cross-sectional area for conduction electrons over a specimen Length $\mathrm{L}$ for (a) a fully dense specimen and (b) a porous specimen. 


$$
\begin{aligned}
& A_{p}=A_{d}\left(1-\frac{\varphi}{\varphi_{0}}\right) \\
& L_{p}=L_{d}\left[\frac{1-\varphi}{1-\frac{\varphi}{\varphi_{0}}}\right]
\end{aligned}
$$

It may be noted here that the tap porosity $\varphi_{0}$, which is the porosity of the starting powder mass after being vibrated, is very important. It is highly dependent on particle size, shape and distribution, and is therefore a paramount determinant of pore size and pore structure after compaction and sintering.

\section{Assessment of Models Using Experimental Results}

The three model Equations (Equations (7)-(9)) discussed above are assessed using experimental results obtained in this work for pure tungsten and pure molybdenum compacted and sintered to obtain sintered skeletons for contact infiltration purposes. The tap densities of the tungsten and molybdenum powders used for the work were $2.81 \mathrm{gm} / \mathrm{cm}^{3}$ and $3.05 \mathrm{gm} / \mathrm{cm}^{3}$ respectively. Thus the relative densities of the vibrated powder mass were $2.81 / 19.3=0.146$ for tungsten, and 3.05/10.2 $=0.30$ for molybdenum (since densities of $\mathrm{W}$ and Mo are 19.3 $\mathrm{gm} / \mathrm{cm}^{3}$ and $10.2 \mathrm{gm} / \mathrm{cm}^{3}$ respectively). Values of $\varphi_{0}$ for the vibrated starting powders of $\mathrm{W}$ and Mo are thus obtained as 0.854 and 0.70 respectively. Table 2 presents the values of the pore volume fractions, $(\varphi)$ and electrical conductivity values $\sigma_{p}$ predicted from the models. The values of electrical conductivity measured experimentally from the sintered $\mathrm{W}$ and Mo skeletons are compared with the values predicted from the models in Figure 6 (for pure tungsten) and Figure 7 (for pure molybdenum). The Figures show that at high values of porosity,

\begin{tabular}{|c|c|c|c|c|c|c|c|c|}
\hline \multicolumn{9}{|c|}{ PURE TUNGSTEN } \\
\hline $\begin{array}{l}\text { Compaction } \\
\text { Pressure } \\
\left(\mathrm{MP}_{\mathrm{a}}\right)\end{array}$ & $\begin{array}{c}\% \\
\text { Porosity }\end{array}$ & $\begin{array}{c}\text { Pore volume } \\
\text { fraction, } \varphi\end{array}$ & $1-\varphi$ & $\begin{array}{l}\text { initial pore vol. } \\
\text { fraction of } \\
\text { vibrated powder, } \varphi_{0}\end{array}$ & $\frac{\varphi}{\varphi_{0}}=\varphi_{R}$ & $\begin{array}{c}\sigma_{\mathrm{p}} \\
\text { (Montes Theory) } \\
(\% \text { IACS })\end{array}$ & $\begin{array}{c}\sigma_{\mathrm{p}}=\sigma_{\mathrm{ef}} \\
\text { Maxwell-Garnett } \\
(\% \text { IACS })\end{array}$ & $\begin{array}{c}\sigma_{\mathrm{p}}=\sigma_{\mathrm{ef}} \\
\text { Bruggeman } \\
(\% \text { IACS })\end{array}$ \\
\hline 100 & 49.5 & 0.495 & 0.505 & 0.854 & 0.580 & 10.78 & 12.50 & 7.95 \\
\hline 150 & 45.0 & 0.450 & 0.550 & 0.854 & 0.527 & 12.57 & 13.86 & 10.03 \\
\hline 200 & 41.0 & 0.410 & 0.590 & 0.854 & 0.480 & 14.12 & 15.11 & 11.88 \\
\hline 250 & 37.5 & 0.375 & 0.625 & 0.854 & 0.439 & 15.55 & 16.24 & 13.50 \\
\hline 300 & 32.0 & 0.320 & 0.680 & 0.854 & 0.375 & 17.74 & 18.10 & 16.04 \\
\hline \multicolumn{9}{|c|}{ PURE MOLYBDENUM } \\
\hline 100 & 42.0 & 0.420 & 0.580 & 0.70 & 0.600 & 8.51 & 14.80 & 11.42 \\
\hline 150 & 37.0 & 0.370 & 0.630 & 0.70 & 0.529 & 10.87 & 16.41 & 13.73 \\
\hline 200 & 34.0 & 0.340 & 0.660 & 0.70 & 0.486 & 12.34 & 17.41 & 15.12 \\
\hline 250 & 28.0 & 0.280 & 0.720 & 0.70 & 0.400 & 15.43 & 19.49 & 17.90 \\
\hline 300 & 25.0 & 0.250 & 0.750 & 0.70 & 0.357 & 17.00 & 20.57 & 19.29 \\
\hline
\end{tabular}

Table 2. Pore volume fractions $(\varphi)$ and Electrical conductivity values $\left(\sigma_{\mathrm{p}}\right)$ Predicted from the models. 


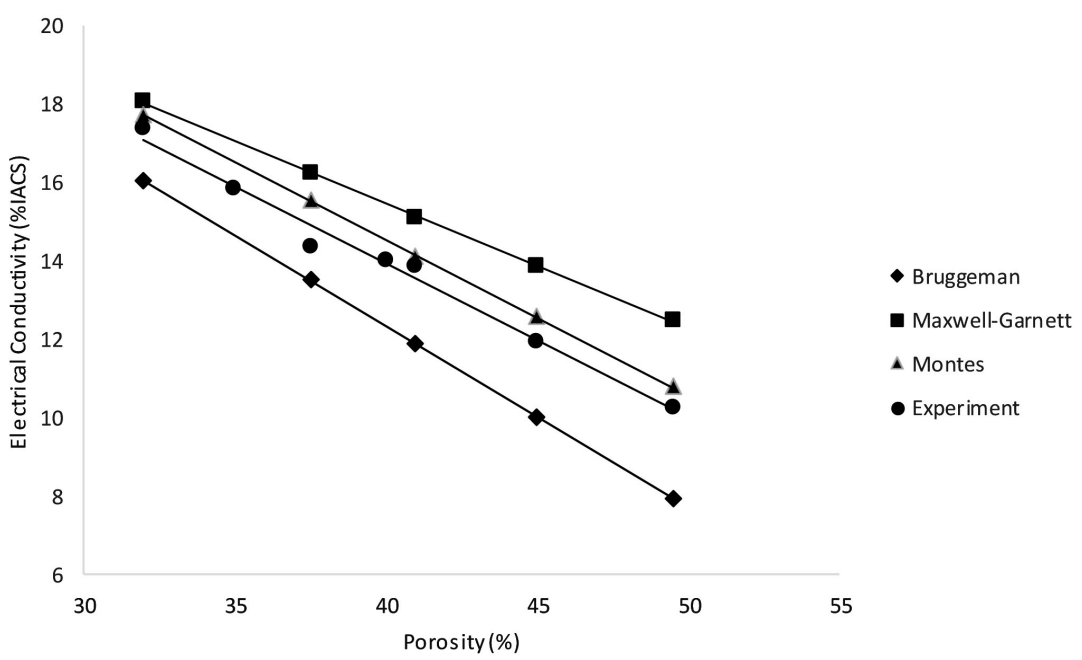

Figure 6. Dependence of Electrical conductivity on porosity of tungsten as calculated from the model equations and as measured experimentally.

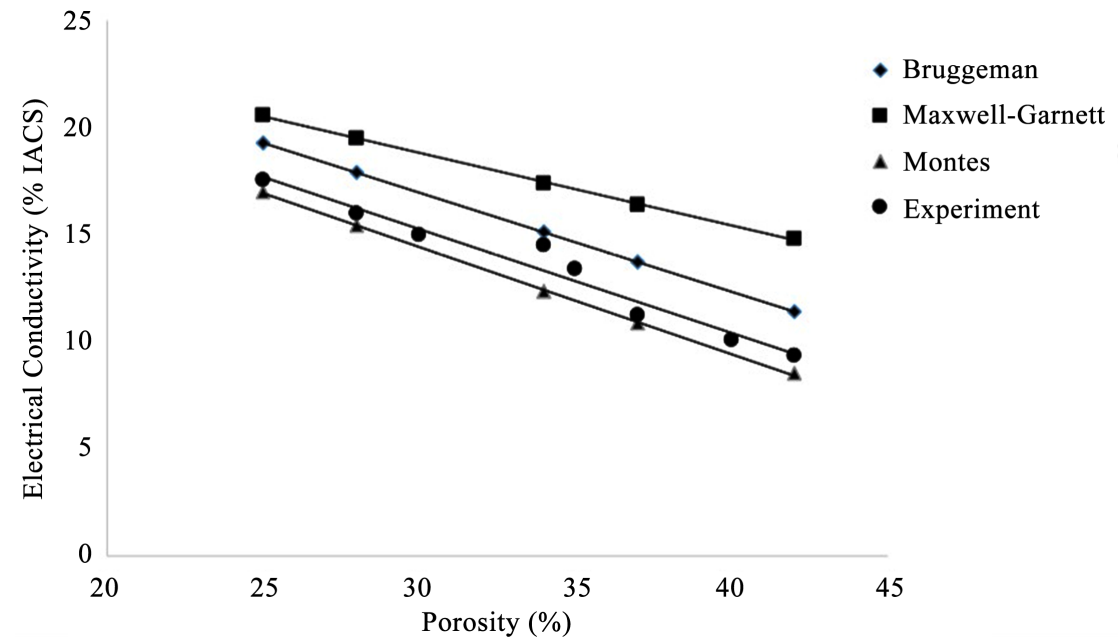

Figure 7. Dependence of electrical conductivity on porosity of molybdenum as calculated from the model equations and as measured experimentally.

there are significant differences in the conductivity values predicted by the models, but at low values of porosity, the differences become much smaller.

These results show that all three models may be depended upon for prediction of the electrical conductivity of sintered porous metals having relatively low levels of porosity $(<20 \%)$. Since actual values of porosity in sintered compacts obtained using the LPS and infiltration techniques are generally lower than about 8\%, the trends shown in Figure 6 and Figure 7 suggest that all three models are acceptable for providing estimates of electrical conductivity from porosity data. It may be noted that the predictions from the Montes model agree reasonably well with the conductivity values obtained experimentally, even at high levels of porosity. Therefore this model, which takes into account the tap density of the starting powder material, may be considered the best for making conductivity estimates even at relatively high levels of porosity. 


\section{Conclusions}

From the results of this work, the following conclusions may be reached:

1) The Spark Plasma Sintering (SPS) process is capable of producing pore-free $\mathrm{W}-\mathrm{Cu}$ and $\mathrm{Mo}-\mathrm{Cu}$ composites, with relative densities in the range of $99 \%$ $100 \%$.

2) With the very high level of densification obtained by the SPS technique, $\mathrm{W}-\mathrm{Cu}$ and $\mathrm{Mo}-\mathrm{Cu}$ sintered compacts with relatively high electrical conductivity can easily be produced. For example, W-40 wt\% $\mathrm{Cu}$ and Mo-40 wt\% Cu with electrical conductivities of $49.3 \%$ IACS and $46.8 \%$ IACS respectively have been developed in this work. These values are substantially higher than those produced by other techniques.

3) From the results of this work, the SPS technique is recommended as the ideal process for producing wear-resistant and arc-erosion resistant composite materials for electrical contact applications.

4) The lower levels of electrical conductivity in specimens obtained by the current commercial techniques of infiltration and liquid phase sintering are mainly due to the residual porosities in specimens produced by these techniques.

5) Three models for predicting the conductivity of porous powder compacts the Maxwell-Garnett, Bruggeman, and Montes models have been assessed. It is found that the Montes model tends to give more accurate predictions because of the extra considerations given to pore size and shape as well as to pore distribution in the continuous matrix.

\section{Conflicts of Interest}

The authors declare no conflicts of interest regarding the publication of this paper.

\section{References}

[1] Gusmano, G., Blanco, A, and Polini, R. (2001) Chemical Synthesis and Sintering Behavior of Highly Dispersed W-Cu Composite Powders. Journal of Materials Science, 36, 901-907. https://doi.org/10.1023/A:1004894900840

[2] Johnson, J.I. and German, R.M. (1994) Chemically Activated Liquid Phase Sintering of Tungsten Copper. The International Journal of Powder Metallurgy, 30, 91-102.

[3] Joo, S.-K., Lee, S.-W. and Ihn, T.-H. (1994) Effect of Cobalt Addition on the Liquid Phase Sintering of W-Cu Prepared by the Fluidized Bed Reduction Method. Metallurgical and Materials Transactions A, 25, 1575-1578. https://doi.org/10.1007/BF02668523

[4] German, R.M. and Johnson, J.I. (1991) Effect of Processing Variables on the Properties of Liquid Phase Sintered Tungsten-Copper Composites. Advances in Powder Metallurgy, 1, 391-405.

[5] Hasse, P. (1989) Selective Laser Sintering of Binary Metallic Powders. MS Thesis, University of Texas, Austin.

[6] Lassner, E. and Schubert, W.D. (1999) Tungsten: Properties, Chemistry, Technology of the Element, Alloys, and Chemical Compounds. Kluwer Academic/Plenum Publishers, NewYork. https://doi.org/10.1007/978-1-4615-4907-9 
[7] Hulbert, D.M., Anders, A., Andersson, J., Lavernia, E.J. and Mukherjee, A.K. (2009) A discussion on the absence of plasma in Spark Plasma Sintering. Scripta Materialia, 60, 835-838. https://doi.org/10.1016/j.scriptamat.2008.12.059

[8] Sharma, N. (2019) Fundamentals of Spark Plasma Sintering (SPS): An Ideal Processing Technique. In: Cavaliere, P., Ed., Spark Plasma Sintering of Materials, Springer, Cham, 21-59. https://doi.org/10.1007/978-3-030-05327-7_2

[9] Munir, Z.A., Anselmi-Tamburini, U. and Ohyanagi, M. (2006) The Effect of Electric Field and Pressure on the Synthesis and Consolidation of Materials: A Review of the Spark Plasma Sintering Method. Journal of Materials Science, 41, 763-777.

https://doi.org/10.1007/s10853-006-6555-2

[10] Biswas, K., He, J.Q., Blum, I.D., Wu, C.-I., Hogan, T.P., Seidman, D.N., Dravid, V.P. and Kanatzidis, M.G. (2012) High-Performance Bulk Thermoelectrics with All-Scale Hierarchical Architectures. Nature, 489, 414-418. https://doi.org/10.1038/nature11439

[11] Yanagiya, S., Van Nong, N., Xu, J.X. and Pryds, N. (2010) The Effect of (Ag, Ni, $\mathrm{Zn}$ )-Addition on the Thermoelectric Properties of Copper Aluminate. Materials, 3 , 318-328. https://doi.org/10.3390/ma3010318

[12] Wang, S.F., Zhang, J., Luo, D.W., Gu, F., Tang, D.Y., Dong, Z.I., Tan, G.E.B., Que, W.X., Zhang, T.S., Li, S., et al. (2013) Transparent Ceramics: Processing, Materials, and Applications. Progress in Solid State Chemistry, 41, 20-54.

https://doi.org/10.1016/j.progsolidstchem.2012.12.002

[13] Kim, B.N., Hiraga, K., Morita, K. and Yoshida, H. (2007) Spark Plasma Sintering of Transparent Alumina. Scripta Materialia, 57, 607-610. https://doi.org/10.1016/j.scriptamat.2007.06.009

[14] Deng, X., Wang, X., Wen, H., Kang. A., Gui, Z. and Li, L. (2006) Phase Transitions in Nanocrystalline Barium Titanate Ceramics Prepared by Spark Plasma Sintering. Journal of the American Ceramic Society, 89, 1059-1064. https://doi.org/10.1111/j.1551-2916.2005.00836.x

[15] Alaniz, J.E., Perez-Gutierrez, F.G., Aguilar, G. and Garay, J.E. (2009) Optical Properties of Transparent Nanocrystalline Yttria Stabilized Zirconia. Optical Materials, 32, 62-68. https://doi.org/10.1016/j.optmat.2009.06.004

[16] Li, J., Cui, B., Wang, H., Lin, Y., Deng, X., Li, M. and Nan, C. (2016) The Effects of Spark Plasma Sintering (SPS) on the Microstructure and Mechanical Properties of $\mathrm{BaTiO}_{3} / 3 \mathrm{Y}-\mathrm{TZP}$ Composites. Materials, 9, 320. https://doi.org/10.3390/ma9050320

[17] Kothari, N.C. (1982) Factors Affecting Tungsten-Copper and Tungsten-Silver Electrical Contact Materials. Powder Metallurgy International, 14, 139-143.

http://pascal-francis.inist.fr/vibad/index.php?action=getRecordDetail\&idt=PASCA L8300449144

[18] Madej, M. and Lezanski, J. (2005) Copper Infiltrated High Speed Steel Based Composites. Archives of Metallurgy and Materials, 50, 871-877.

[19] Madej, M. (2010) The Tribological Properties of High Speed Steel Based Composites. Archives of Metallurgy and Materials, 55, 61-68.

[20] Madej, M. (2012) Silver-Based Infiltrated Composites. Archives of Metallurgy and Materials, 57, 605-612. https://doi.org/10.2478/v10172-012-0064-X

[21] Ghaderi, H.A., Arabi, H. and Rastegari, S. (2011) Reduction of Sintering Temperature of Porous Tungsten Skeleton used in Production of W-Cu Composites by U1tra-High Compaction Pressure of Tungsten Powder. Advanced Materials Research, 264-265, 807-812. https://doi.org/10.4028/www.scientific.net/AMR.264-265.807

[22] Masakama, H., Tetsunume, K., Chen, Y.Q., Hiromu, K. and Mamoru, M. (2007) In- 
fluence of Porosity and Pore Size on Electrical Resistivity of Porous Aluminum Produced by Spacer Method. Materials Transactions, 48, 32-36.

[23] El, K.H., Cordier, A., Batis, N., Siebert, E., Georges, S. and Steil, M.C. (2017) Effect of Porosity on the Electrical Conductivity of LAMOX Materials. Solid State Ionics, 304, 75-84. https://doi.org/10.1016/j.ssi.2017.03.028

[24] Vincent, C., Silvain, J.E., Heintz, J.M. and Chandra, N. (2012) Effect of Porosity on the Thermal Conductivity of Copper Processed by Powder Metallurgy. Journal of Physics and Chemistry of Solids, 73, 499-504. https://doi.org/10.1016/j.jpcs.2011.11.033

[25] Montes, J.M., Cuevas, F.G. and Cintas, J. (2008) Porosity Effect on the Electrical Conductivity of Sintered Powder Compacts. Applied Physics A, 92, 375-380. https://doi.org/10.1007/s00339-008-4534-y

[26] Maxwell, J.C. (1998) A Treatise on Electricity and Magnetism. Clarendon Press, Dover, New York.

[27] Malachlan, D.S. (1986) Equations for the Conductivity of Macroscopic Mixtures. Journal of Physics C: Solid State Physics, 19, 1339-1354.

https://doi.org/10.1088/0022-3719/19/9/007

[28] Montes, J.M., Rodriguez J.A. and Herrera, E.J. (2003) Thermal and Electrical Conductivities of Sintered Powder Compacts. Powder Metallurgy, 46, 251-256. https://doi.org/10.1179/003258903225008544

[29] Montes-Hernández, G., Fernández-Martínez, A., Charlet, L., Tisserand, D. and Renard, F. (2008) Textural Properties of Synthetic Nano-Calcite Produced by Hydrothermal Carbonation of Calcium Hydroxide. Journal of Crystal Growth, 310, 2946-2953. https://doi.org/10.1016/j.jcrysgro.2008.02.012

[30] Bruggeman, D.A.G. (1935) Berechnung Verschiedener Physikalischer Konstanten von Heterogenen Substanzen. I. Dielektrizitatskonstanten und Leitfahigkeiten der Mischkorper aus Isotropen Substanzen. Annalen der Physik, 416, 636-664. https://doi.org/10.1002/andp.19354160705

[31] Bergman, D.J. (1978) The Dielectric Constant of a Composite Material-A Problem in Classical Physics. Physics Reports, 43, 377-407. https://doi.org/10.1016/0370-1573(78)90009-1

[32] Bergman, D.J. (1982) Rigorous Bounds for the Complex Dielectric Constant of a Two-Component Composite. Annals of Physics, 138, 78-114. https://doi.org/10.1016/0003-4916(82)90176-2 